\title{
A Technical Note: Orientation of Cracks and Hydrology in a Shrink-Swell Soil
}

\author{
Takele M. Dinka ${ }^{1}$, Robert J. Lascano ${ }^{2 *}$ \\ ${ }^{1}$ Department of Soil and Crop Sciences, Texas A\&M University, College Station, TX, USA; ${ }^{2}$ USDA-ARS ${ }^{\#}$ Cropping Systems Re- \\ search Laboratory, Wind Erosion and Water Conservation Research Unit, Lubbock, TX, USA. \\ Email: takele2004@yahoo.com, ${ }^{*}$ Robert.Lascano@ars.usda.gov
}

Received March 23 ${ }^{\text {rd }}, 2012$; revised April 25 ${ }^{\text {th }}$, 2012; accepted May 4 $4^{\text {th }}, 2012$

\begin{abstract}
Crack orientations are an important soil physical property that affects water flow, particularly in vertic soils. However, the spatial and temporal variability of crack orientations across different land uses and gilgai features is not welldocumented and addressed in hydrology models. Thus; there is a need to quantify crack orientations for different land uses and to incorporate their spatial and temporal dynamics into hydrological models. Our objectives were to document the spatial variability of cracks orientations across two land uses and to demonstrate the potential importance of crack orientation related to the hydrology of Vertisols. The exploratory field measurements of the spatial distribution of crack orientations across two Vertisol catenae of two land uses and gilgai features are presented. The field survey showed the complexity of crack geometry in a field, the potential impact of crack orientation on Vertisol hydrology and the challenges associated with measurement of crack orientations.
\end{abstract}

Keywords: Crack; Orientation; Hydrology

\section{Introduction}

Vertisols that shrink while drying and swell while wetting can damage building foundations, roads, utilities and septic tanks. The management of Vertisols for agricultural production such as fertilizer use, crop selection, soil tillage, irrigation, and soil erosion is more problematic compared to other soil group [1,2]. When shrink-swell soils dry, cracks are formed, and these cracks facilitate rapid transport of surface water into the sub-soil through preferential flow. Furthermore, rapid transport of surface water to the sub-soil reduces runoff and enhances flow of chemicals to sub-soils and ground waters [3-5]. Hence, the frequency, size and rate of crack development influence the transport of water, nutrients and gases in the soil profile and plant growth processes in Vertisols [3,4]. Therefore, measurement of soil cracks is important to monitor not only surface and sub-surface flow of water, but also to monitor flow of gases in the soil-atmosphere continuum, and to understand how roots grow and their penetration pattern in the soil.

\footnotetext{
* Corresponding author.

\#The U.S. Department of Agriculture (USDA) prohibits discrimination in all its programs and activities on the basis of race, color, national origin, age, disability, and where applicable, sex, marital status, familial status, parental status, religion, sexual orientation, genetic information, political beliefs, reprisal, or because all or part of an individual's income is derived from any public assistance program.
}

The importance of studying cracks and its field of application is well documented by several researchers, e.g., [3-7]. Soil cracks affect several components of the water balance, i.e., infiltration, drainage and runoff, therefore impacting the hydrology of the soil. For example, soil cracks enhance rapid flow of water into sub-soils [4] and they increase the infiltration rate of water impacting surface runoff [8]. The main soil physical property that is associated with cracks is shrinkage and the associated crack formation that impacts water flow is crack depth, rate of development, crack area density and orientation. Additional information on challenges and limitations in understanding the shrink-swell and crack dynamics of Vertisol soils is given by Dinka and Lascano [9].

Most studies of shrinkage and cracking of Vertisols have focused on the size and areal density of cracks, e.g., [4,10-12] and not on the orientation of cracks. As a result, hydrology models that account for the orientation of cracks are not available because the genesis and formation of cracks orientations and their spatial variability across different land uses are poorly understood. The orientation of cracks can impact and affect the surface flow and capture of water. For example, cracks that are parallel to the direction of overland flow of water might capture less water than cracks that are perpendicular. However, current hydrological models like Soil Water As- 
sessment Tool (SWAT) [3] do not incorporate this crack property, which may result in misrepresentation of water flow in a Vertisol. The orientation of cracks may also vary spatially with presence and shape of a Vertisol features such as gilgai. In the Blackland Prairie of Texas, the presence of linear and circular gilgai is reported [13]. Therefore, the spatial variability of crack orientation on a land with and without gilgai and with linear and without circular gilgai can also have a different impact on the flow water in the soil. However, no attempt has been done to demonstrate the spatial variability of cracks orientations in a field and their associated impact on the hydrology of the soil. The objective of this technical note was two fold. First, to investigate the variability of cracks orientation across two land uses, and second, to demonstrate the importance of crack orientation in studying the hydrology of Vertisols.

\section{Methodology of the Survey}

The survey was conducted at the USDA-ARS Grassland, Soil and Water Research Laboratory near Riesel, TX. The climate is warm and sub-humid with a mean annual rainfall of $910 \mathrm{~mm}$. Two watersheds with different land use systems were selected for the survey of crack orientation. The land use types were native prairie and grazed pasture. The dominant soil in the area is Houston Black (Fine, smectitic, thermic Udic Haplusterts) that consists of very deep, moderately well drained, very slowly permeable soils formed from weakly consolidated calcareous clays and marls of Cretaceous age [14]. The dominant vegetation in the native prairie is little Bluestem (Schizachyrium scoparium) grass and in the grazed pasture is Costal Bermuda (Cynodon dactylon) grass. The average slope of the native prairie and grazed pasture is $5 \%$ and 2\%, respectively (Figure 1 and Figure 2).

A survey was conducted on 11 August 2009, when there were many large cracks in the soil. Three slopewise transects were selected for the survey in each watershed (Figure 1 and Figure 2). The final destination of the transect survey was at the outlet of the watershed. The length of the transect lines ranged from $100-120 \mathrm{~m}$ in the grazed pasture (1.5 ha) and from $110-125 \mathrm{~m}$ in the native prairie (1.4 ha) watersheds.

The orientations of the cracks were categorized as parallel, perpendicular, or irregular (neither parallel nor perpendicular) with respect to the slope of the land and flow direction of runoff. A crack $(\geq 10 \mathrm{~mm})$ was considered parallel when it followed the direction of runoff flow; and perpendicular when it was parallel to the contour, both within \pm 30 degrees of tolerance; and irregular when it was neither parallel nor perpendicular. Finally, the difference and similarities in cracks orientations among and within the land use types were compared.

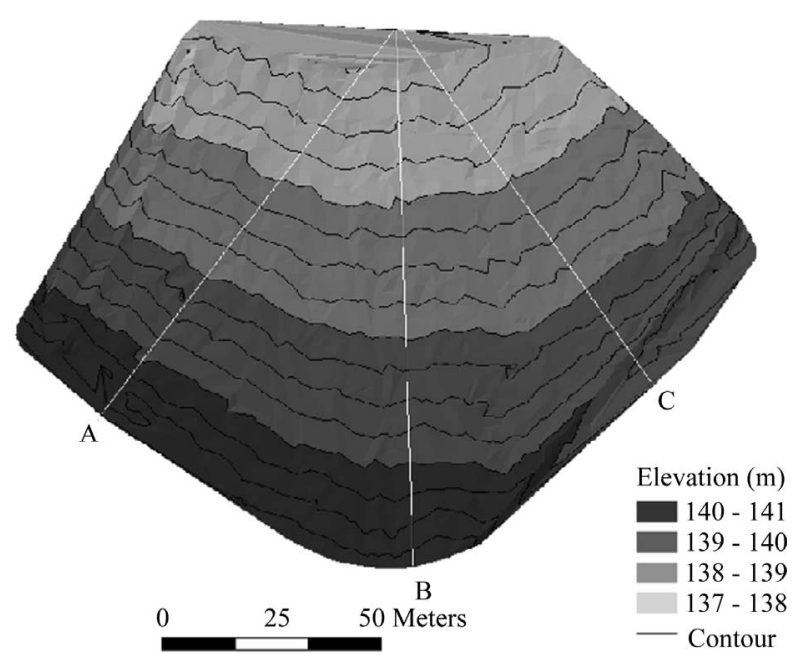

Figure 1. Topographic map of a native prairie with a $0.25 \mathrm{~m}$ contour, located at the USDA-ARS Blackland, Soil and Water Research Laboratory, Riesel, TX. Letters A, B and C indicate the location where surveys started and lines indicate transects of the survey.



Figure 2. Topographic map of the Grazed pasture with a $0.25 \mathrm{~m}$ contour, located at the USDA-ARS Blackland, Soil and Water Research Laboratory, Riesel, TX. Letters A, B and $C$ indicate the locations where the survey started and lines indicate transects of the survey.

\section{Field Observation}

The number of large cracks observed on the native prairie and grazed pasture from the three transects were 53 and 58, respectively (Figure 3). Among the 53 cracks in the native prairie, $61 \%$ were oriented parallel to the flow direction, $28 \%$ were oriented perpendicular to the flow direction and the remaining $11 \%$ were classified as irregular to the flow direction. In the grazed pasture the 58 cracks had a distribution of $48 \%$ parallel, $45 \%$ perpendicular and 7\% irregular. 


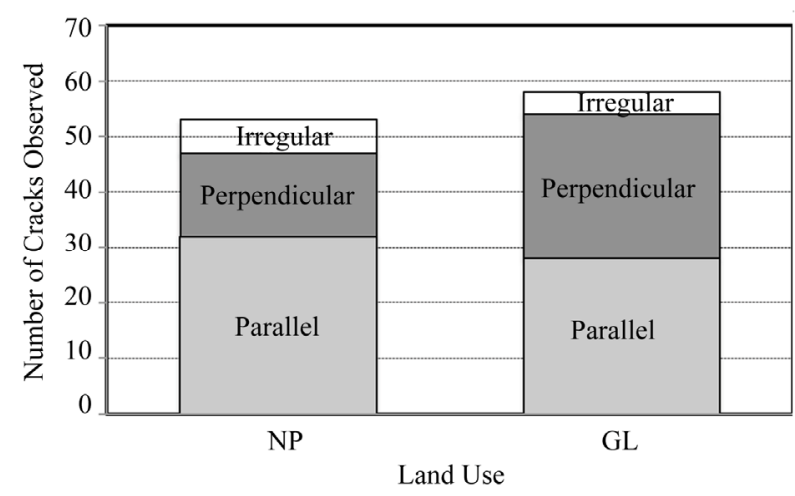

Figure 3. Distribution of irregular, perpendicular and parallel crack orientation on a native prairie (NP) and grazed pasture (GL) at the USDA-ARS Blackland, Soil and Water Research Laboratory, Riesel, TX. The survey was conducted on 11 August 2009.

The survey showed that most cracks, $61 \%$, were oriented parallel to the direction of flow in the native prairie. However, number of parallel (48\%) and perpendicular (45\%) cracks was not considerably different in the grazed pasture. In both lands uses, the frequency of occurrence of irregular cracks was less compared to parallel and perpendicular cracks. In the native prairie, the percent of irregular cracks was $11 \%$ and $7 \%$ in the grazed prairie. The difference in orientations of cracks among the land use types could be due to not only the differrences in vegetation cover, but also to the inherent size and shape of gilgai microhigh and microlow topographic and subsurface features. In both land uses, cracks that oriented parallel were mostly observed on the "lower points" of the gilgai microtopography where runoff would flow.

Two major types of gilgai were observed in the field: circular and linear. Circular gilgai is a Vertisol feature common in the Texas Gulf Coast Prairie, while linear gilgais are formed on sloping land [15]. The gilgais in the native prairie were very elongated (up to $10 \mathrm{~m}$ length and 0.50 to $1 \mathrm{~m}$ width) in the direction of a slope that formed a natural channel for flow of runoff. The shape of gilgais in the grazed pasture was circular with a diameter of up to $3 \mathrm{~m}$ and a depth of up to $0.10-0.20 \mathrm{~m}$. The existence of parallel cracks in slopewise elongated microlows, where runoff would flow, shows the possible influence of cracks orientation on flow and distribution of water in a vertic watershed. In contrast, a crack orientation in a circular microlow may not considerably affect the amount of runoff generated from a vertic watershed. This is because the circular gilgai, regardless of the orientation of cracks formed inside, would capture water. The influence of crack orientation on runoff and water distribution depends on the existence and type of microlows. Cracks that oriented parallel to the runoff direction would likely enhance more surface runoff as compared to cracks ori- ented horizontally. However, since parallel cracks likely trap greater volume of surface runoff, the volume of subsurface runoff and soil water distribution around the horizontally oriented cracks could be high. Therefore, the commonly observed spatial variability in occurrence of gilgai [16] and orientations of cracks need to be addressed in a study of hydrology of shrink-swell soils.

\section{Challenges in Quantifying Orientation of Cracks}

Attempts have been made to study crack geometry using photography in a laboratory [17] and in a field [18] setting and a review on problems in studying the shrinkswell and crack dynamics of Vertisol soils is given by Dinka and Lascano [9]. The photographic technique has the advantage that data can be easily and continuously acquired and it is nondestructive. However, this technique does not provide other crack information such as depth of cracks and it is difficult to get a quality data when the land has vegetation. The direct measurement of crack orientation in a field is another technique that is available to measure crack geometry but its application is challenging, especially on a wide area. First, categorizing the direction of a crack is subjective, especially when it is neither clearly parallel nor perpendicular. Second, apart from the presence of gilgai, the existence of any other microtopographic feature on the land has to be considered to classify the direction of the crack orientation and deciding whether the influence of the microtopography is important or not. If it is important, categorizing the direction of cracks should not be based on the general slope direction of the entire land but rather the classification should follow the slope of the microtopography because the aim of the categorization is to determine their impact on runoff. This shows that the decision is sitespecific and also based on the flow direction of a runoff on that particular site. In addition, quantifying the contribution of minor cracks that might be part, i.e., branch to a major crack also represents a challenge to categorize the orientation of the cracks. Use of a survey quality geographic positioning system (GPS) to measure crack location would help reduce these problems.

\section{Conclusion}

The spatial variability of cracks orientations across two land uses was investigated and the potential importance of crack orientation and impact on the hydrology of Vertisols was demonstrated. Results from this study showed that crack orientation has an impact on the amount of runoff; hence, hydrological models should incorporate not only the size, depth and density of cracks but also their orientation. Results also pointed out some of the challenges associated with a study of crack orientations, 
and suggested the importance of developing simple and practical guidelines to determine crack orientation or other techniques that could capture all the necessary crack information such as the size, depth, density and orientation of cracks needs to be used. Further studies are necessary to understand whether there is a spatial pattern to crack orientations and whether there is a trend on the distance between wide cracks.

\section{Acknowledgments}

The Texas AgriLife Research, and a Cooperative Agreement with the USDA NRCS Texas Soil Survey and National Science Foundation Grant No. EAR 0911317 in part supported this work.

\section{REFERENCES}

[1] R. Dudal and H. Eswaran, "Distribution, Properties, and Classification of Vertisols," In: L. P. Wilding and R. Puentes, Eds., Publication Soil Management Support Services, US Department of Agriculture, Natural Resources Conservation Service, Washington DC, 1988, pp. 1-22.

[2] D. Smiles and P. A. C. Raats, "Hydrology of Swelling Clay Soils,” In: M. G. Anderson, Ed., Encyclopedia of Hydrological Sciences, Wiley, Chichester, Chapter 67, 2005, pp. 1011-1026.

[3] J. G. Arnold, K. N. Potter, K. W. King and P. M. Allen, "Estimation of Soil Cracking and the Effect on Surface Runoff in a Texas Blackland Prairie Watershed," Hydrological Processes, Vol. 19, No. 3, 2005, pp. 589-603. doi:10.1002/hyp.5609

[4] K. K. Bandyopadhyay, M. Mohanty, D. K. Painuli, A. K. Misra, K. M. Hati, K. G. Mandal, P. K. Ghosh, R. S. Chaudhary and C. L. Acharya, "Influence of Tillage Practices and Nutrient Management on Crack Parameters in a Vertisol of Central India,” Soil Tillage Research, Vol. 71, No. 2, 2003, pp. 133-142. doi:10.1016/S0167-1987(03)00043-6

[5] R. P. S. Júnior and J. J. Boesten, "Simulation of Pesticide Leaching in a Cracking Clay Soil with the PEARL Model,” Pest Management Science, Vol. 61, No. 5, 2005, pp. 432-448. doi:10.1002/ps.1004

[6] J. J. B. Bronswijk, "Relation between Vertical Soil Movements and Water-Content Changes in 457 Cracking Clays," Soil Science Society of American Journal, Vol. 55, No. 5, 1991, pp. 1220-1226. doi:10.2136/sssaj1991.03615995005500050004x
[7] V. Y. Chertkov, "Using Surface Crack Spacing to Predict Crack Network Geometry in Swelling Soils," Soil Science Society of American Journal, Vol. 64, No. 6, 2000, pp. 1918-1921. doi:10.2136/sssaj2000.6461918x

[8] V. Novák, "Soil-Crack Characteristics-Estimation Methods Applied to Heavy Soils in the NOPEX Area," Agricultural Forest Meteorology, Vol. 98-99, 1999, pp. 501507. doi:10.1016/S0168-1923(99)00119-7

[9] T. M. Dinka and R. J. Lascano, "Challenges and Limitations in Studying the Shrink-Swell and Crack Dynamics of Vertisol Soils,” Open Journal of Soil Science, 2012, Article in Press.

[10] I. Daniells, "Degradation and Restoration of Soil Structure in a Cracking Grey Clay Used for Cotton Production,” Australian Journal of Soil Research, Vol. 27, No. 2, 1989, pp. 455-469. doi:10.1071/SR9890455

[11] A. Sz. Kishné, C. L. S. Morgan, Y. Ge and W. L. Miller, "Antecedent Soil Moisture Affecting Surface Cracking of a Vertisol in Field Conditions," Geoderma, Vol. 157, No. 3-4, 2010, pp. 109-117. doi:10.1016/j.geoderma.2010.03.020

[12] A. Sz. Kishné, C. L. S. Morgan and W. L. Miller, "Vertisol Crack Extent Associated with Gilgai and Soil Moisture in the Texas Gulf Coast Prairie,” Soil Science Society of American Journal, Vol. 73, No. 4, 2009, pp. 12211230. doi:10.2136/sssaj2008.0081

[13] T. M. Dinka, "Shrink-Swell Dynamics of Vertisol Catenae under Different Land Uses,” Ph.D. Dissertation, Texas A\&M University, College Station, 2011.

[14] USDA-NRCS, 1997, Accessed on 10 June 2009. www2.ftw.nrcs.usda.gov/osd/dat/H/HEIDEN.html

[15] W. L. Miller, A. S. Kishné, and C. L. S. Morgan, "Vertisol Morphology, Classification, and Seasonal Cracking Patterns in the Texas Gulf Coast Prairie,” Soil Survey Horizon, Vol. 51, No. 1, 2010, pp. 10-16.

[16] L. P. Wilding, D. Williams, W. Miller, T. Cook and H. Eswaran, "Close Interval Spatial Variability of Vertisols: A Case Study in Texas,” In: J. M. Kimble, Ed., Proceedings of Sixth International Soil Correlation Meeting (VI ISCOM): Characterization, Classification and Utilization of Cold Aridisols and Vertisols, USDA-SCS, Natl. Soil Survey Ctr., Lincoln, 1990, pp. 232-247.

[17] X. Peng, R. Horn, S. Peth and A. Smucker, "Quantification of Soil Shrinkage in 2D by Digital Image Processing of Soil Surface,” Soil Tillage Research, Vol. 91, No. 1-2, 2006, pp. 173-180. doi:10.1016/j.still.2005.12.012

[18] B. Velde, "Structure of Surface Cracks in Soil and Muds,” Geoderma, Vol. 93, No. 1-2, 1999, pp. 101-124. 